\title{
EVIDENCIA SEROLÓGICA DE LA PRESENCIA DEL VIRUS HERPES CANINO TIPO 1 EN LA PROVINCIA DE LIMA
}

\author{
Serological Evidence of the Presence of Canine Herpes Virus Type 1 in Lima \\ Province
}

Vladimir Góngora A. ${ }^{1}$, Nieves Sandoval Ch. ${ }^{1,3}$ y Alberto Manchego S. ${ }^{2}$

\section{RESUMEN}

\begin{abstract}
El Virus Herpes Canino tipo 1 (VHC-1) es responsable de la enfermedad hemorrágica canina en cachorros menores de cuatro semanas de vida y de algunos problemas reproductivos en perras adultas. En el Perú, la enfermedad no ha sido reportada, aunque existen hallazgos que sugieren su presencia. El objetivo del presente estudio fue demostrar la presencia de anticuerpos contra el VHC-1 entre la población canina con antecedentes asociados a problemas reproductivos. Se recolectaron muestras de sangre de 28 animales procedentes de siete distritos de la provincia de Lima que tuvieron algún antecedente relacionado a problemas reproductivos o mortalidad neonatal. Las muestras fueron analizadas con la prueba de inmunofluorescencia indirecta (IFI) donde nueve canes $(32 \pm 17 \%)$ resultaron positivos.
\end{abstract}

Palabras clave: serología, canino, fallas reproductivas, IFI, Lima

\section{Abstract}

The canine Herpesvirus type $1(\mathrm{CHV}-1)$ is responsible for the canine hemorrhagic disease in puppies aged less than four weeks and for some reproductive problems in adult bitches. In Peru, the disease has been not reported, although there are findings suggesting its presence. Thus, the aim of this study was to show the presence of antibodies against CHV-1 among the canine population associated with history of reproductive problems. Blood samples from 28 animals belonging to seven districts of the province of Lima were collected. These dogs had a history of reproductive problems or neonatal mortality. Samples were submited to the indirect immunofluorescense test (IFAT), and nine of them $(32 \pm 17 \%)$ were positive to the test.

Key words: serology, canine, reproductive failures, IFAT, Lima

\footnotetext{
${ }^{1}$ Laboratorio de Histopatología, ${ }^{2}$ Laboratorio de Microbiología y Parasitología Veterinaria, Facultad de Medicina Veterinaria, Universidad Nacional Mayor de San Marcos, Lima

${ }^{3}$ E-mail: nsandovalc@unmsm.edu.pe
} 


\section{INTRODUCCIÓN}

El Virus Herpes Canino tipo 1 (VHC1) fue identificado por primera vez en 1965 $\mathrm{y}$, desde entonces, es considerado como responsable de la Enfermedad Hemorrágica Canina (EHC) (Ronsse et al., 2003). El virus puede transmitirse in utero, así como por secreciones oronasales, contacto sexual y, rara vez, por fomites (Carmichael y Greene, 1998). La replicación viral en adultos se restringe a las vías genitales, tonsilas, ganglios linfáticos retrofaríngeos y bronquiales $\mathrm{y}$, ocasionalmente, a los pulmones.

En cachorros recién nacidos, la infección primaria se disemina por todo el organismo, siendo mortal en animales menores de cuatro semanas (Carmichael, 1999). El herpesvirus canino puede localizarse en los ganglios nerviosos donde permanece latente, siendo reactivado y liberado esporádicamente luego de algún evento estresante, constituyendo una fuente de infección permanente para los animales susceptibles (Okuda et al., 1993b); sin embargo, no se ha observado signos sugerentes de enfermedad en hembras que pierden camadas por VHC1. Las infecciones transplacentarias pueden ocurrir en la mitad o último tercio de gestación ocasionando abortos, partos prematuros o recién nacidos débiles (Carmichael, 1999); así mismo, el tratamiento suele ser ineficaz debido al curso rápido de la enfermedad en cachorros (Merck, 2000; Morgan et al., 2003).

En el país, la presencia del VHC no ha sido notificada; sin embargo, se tiene como referencia la necropsia de unos cachorros en 1998, donde se hallaron lesiones sugerentes de la enfermedad, y otro caso ocurrido recientemente, donde al examen histopatológico de unos cachorros muertos con signos de enfermedad respiratoria aguda, se hallaron corpúsculos de inclusión intranucleares en diversos tejidos, lesión característica de las enfermedades producidas por herpesvirus (N. Sandoval, Lima, comunicación personal). Por tal motivo, el objetivo del presente estu- dio fue demostrar la presencia de anticuerpos contra el VHC-1 en una población canina de la provincia de Lima con antecedentes asociados a problemas reproductivos.

\section{Materiales y Métodos}

Se utilizaron animales procedentes de los distritos de San Juan de Lurigancho, San Juan de Miraflores, Santiago de Surco, San Borja, Lurín, Cieneguilla y La Molina, pertenecientes a la provincia de Lima, entre los meses de noviembre del 2004 y abril del 2005. No se hizo distinción de sexo, edad o raza, pero debían tener algún antecedente relacionado con problemas reproductivos, tales como aborto, mortalidad neonatal, infertilidad o reabsorción embrionaria en el caso de hembras, y en el caso de los machos, estos fueron cruzados con hembras con alguno de los antecedentes mencionados. Además, se muestrearon animales provenientes de madres que tuvieron algún episodio abortivo, sobrevivientes de camadas con alta mortalidad y aquellos que presentaron signos respiratorios agudos durante las primeras semanas de vida.

Para el cálculo del tamaño muestral $(\mathrm{n}=28)$ se empleó la fórmula de prevalencia límite (Ahlbon y Norell, 1990) al 10\%, debido a que no existen trabajos previos en el país, ni en países vecinos que proporcionen datos numéricos del estado actual de la enfermedad.

Las muestras de sangre fueron obtenidas por punción de la vena cefálica, colectadas en tubos vacutainer e identificadas apropiadamente. El suero obtenido fue separado y almacenado a $-20^{\circ} \mathrm{C}$ hasta su procesamiento con la prueba de inmunofluorescencia indirecta (IFI), empleando el kit comercial Veterinary Medical Research and Development-VMRD (Pullman, WA-USA). La muestra fue considerada positiva cuando se observó una fluorescencia similar a la del control positivo y negativa cuando no se observó dicha fluorescencia.. 
Cuadro 1. Resultados de la prueba IFI para el virus Herpes Canino Tipo 1(VHC-1) en caninos de la provincia de Lima, según su procedencia, edad, sexo y antecedentes reproductivos

\begin{tabular}{|c|c|c|c|c|}
\hline Procedencia & $\operatorname{Edad}^{1}$ & $\mathrm{Sexo}^{2}$ & Antecedentes & Resultados \\
\hline \multirow{2}{*}{ Cieneguilla } & 2 & $\mathrm{H}$ & Reabsorción embrionaria & - \\
\hline & 10 & $\mathrm{H}$ & Aborto + reabsorción embrionaria & + \\
\hline \multirow{3}{*}{ Lurín } & 10 & $\mathrm{H}$ & Mortalidad neonatal en crías & + \\
\hline & 5 & $\mathrm{H}$ & Mortalidad neonatal en crías & + \\
\hline & 2 & M & Cruce, mortalidad de crías & + \\
\hline \multirow{2}{*}{ La Molina } & 3 & M & Cruce con hembra que abortó & + \\
\hline & 3 & $\mathrm{H}$ & Abortó & - \\
\hline \multirow{2}{*}{ San Borja } & 9 & M & Cruce con hembra que abortó & + \\
\hline & 2 & $\mathrm{H}$ & Abortó, negativo a Brucella sp. & + \\
\hline \multirow{6}{*}{ S.J. Lurigancho } & 0.7 & M & Sobrev. de mortalidad neonatal & + \\
\hline & 2 & M & Sobrev. de mortalidad neonatal & - \\
\hline & 2 & M & Infertilidad & - \\
\hline & 5 & $\mathrm{H}$ & Mortalidad neonatal en crías & - \\
\hline & 4 & $\mathrm{H}$ & Mortalidad neonatal en crías & - \\
\hline & 0.7 & $\mathrm{M}$ & Sobrev. de mortalidad neonatal & + \\
\hline \multirow{6}{*}{ S. J. Miraflores } & 1 & $\mathrm{H}$ & Cría de perra que abortó & - \\
\hline & 9 & M & Cruce con hembra que aborto & - \\
\hline & 4 & $\mathrm{H}$ & Abortó & - \\
\hline & 3 & M & Sobrev. de mortalidad neonatal & - \\
\hline & 3 & M & Muerto por enfermedad respiratoria & - \\
\hline & 4 & M & Sobrev. de mortalidad neonatal & - \\
\hline \multirow{7}{*}{ S. de Surco } & 3 & $\mathrm{H}$ & Abortó & - \\
\hline & 4 & $\mathrm{H}$ & Mortalidad neonatal en crías & - \\
\hline & 3 & M & Cruce con hembra que abortó & - \\
\hline & 0.3 & $\mathrm{H}$ & Muerto por enfermedad respiratoria & - \\
\hline & 0.2 & $\mathrm{H}$ & Muerto por enfermedad respiratoria & - \\
\hline & 0.1 & M & Muerto por enfermedad respiratoria & - \\
\hline & 0.3 & $\mathrm{H}$ & Muerto por enfermedad respiratoria & - \\
\hline Total & & & $\mathrm{n}=28$ & $9(32 \%)$ \\
\hline
\end{tabular}

${ }^{1}$ Edad en años

${ }^{2} \mathrm{H}$ : hembra, M: macho

\section{Resultados y Discusión}

De los 28 sueros procesados, nueve (32 $\pm 17 \%$, frecuencia \pm intervalo de confianza al $95 \%)$ presentaron inmunofluorescencia posi- tiva al VHC-1 (Cuadro 1). No se encontró una relación aparente entre edad, sexo y distrito de procedencia, aunque tampoco se hizo una prueba estadística al respecto, debido al diseño del estudio. 
Pese a que todos los animales bajo estudio tenían alguna asociación con problemas reproductivos, sólo el 32\% resultó positivo, lo que indicaría que la etiología de estos problemas estaría relacionada con otros agentes, además del VHC-1.

La historia reproductiva de los animales positivos es compatible con la enfermedad. Así los dos machos positivos habían tenido contacto sexual con perras con historias previas de aborto o de alta mortalidad en su camada y, por lo tanto, podrían haber estado pasando por un episodio recurrente de una infección (Okuda et al., 1993a). Asimismo, perras con historia de aborto, reabsorción embrionaria y con alta mortalidad en sus crías coincide con reportes de otros autores respecto a la presentación de esta enfermedad (Carmichael y Greene, 1998, Ronsse et al., 2003).

\section{Conclusiones}

En la provincia de Lima existe un 10\% de serorreactores al virus Herpes Canino tipo 1 entre la población canina con antecedentes relacionados a problemas reproductivos.

\section{Literatura Citada}

1. Ahlbom A, Norell S. 1990. Introduction to modern epidemiology. $2^{a}$ ed. USA: Epidemiol Resource. p 24-29.
2. Carmichael L. 1999. Enfermedades virales de los cachorros recién nacidos. Estado actual del Herpesvirus canino y virus diminuto de los caninos (Parvovirus canino-1). En: International Veterinary Information Service. New York. [Internet], [8 diciembre 2004]. Disponible en: www.ivis.org/advances/ Infect_Dis_Carmichael/carmichael_es/ chapter_frm.asp?LA=2.

3. Carmichael L, Greene C. 1998. Infección por Herpesvirus Canino. En: Greene. Enfermedades infecciosas de perros y gatos. $2^{\mathrm{a}}$ ed. México: Interamericana Mc Graw-Hill. p 31-36.

4. Merck. 2000. El manual Merck de veterinaria. $5^{\mathrm{a}}$ ed. Barcelona: Océano. $\mathrm{p}$ 618-619.

5. Morgan R, Bright R, Swartout M. 2003. Clínica de pequeños animales. $4^{\mathrm{a}}$ ed. Madrid: Elsevier. p 1093-1094.

6. Okuda Y, Hashimoto A, Yamaguchi T, Fukushi H, Mori S, Tani M, Hirai K, Carmichael L. 1993a. Repeated Canine Herpesvirus (CHV) reactivation in dogs by an immunosuppressive drug. Cornell Vet 83: 291-302.

7. Okuda Y, Ishida K, Hashimoto A, Yamaguchi T, Fukushi H, Hirai K, Carmichael L. 1993b. Virus reactivation in bitches with a medical history of herpesvirus infection. Am J Vet Res 54: 551-554.

8. Ronsse V, Poulet H, Verstege J, Thirty E. 2003. L'herpèsvirose canine. Ann Méd Vét 147: 65-76. 